\title{
The impact of urban land misallocation on inclusive green growth efficiency: evidence from China
}

\author{
Qin $\mathrm{He}^{1} \cdot$ Juntao $\mathrm{Du}^{2}$ (D) \\ Received: 10 April 2021 / Accepted: 7 August 2021 / Published online: 14 August 2021 \\ (C) The Author(s), under exclusive licence to Springer-Verlag GmbH Germany, part of Springer Nature 2021
}

\begin{abstract}
Inclusive green growth (IGG), as a new way to attain sustainable development, aims to achieve comprehensive and coordinated economic, social, and environmental development. How to define IGG and explore its driving factors is key to realizing IGG. This study takes China as an example, using panel data from 30 provinces in Mainland China from 2009 to 2018 for research. The epsilon-based measure (EBM) model and Global Malmquist-Luenberger (GML) index are used to evaluate China's IGG, and a spatial panel regression model of the impact of urban land resource misallocation on IGG is established. The research found that (1) China's IGG level from 2009 to 2018 displayed an upward trend, and combined with exploratory spatial data analysis (ESDA), it was found that IGG has an obvious spatial correlation; (2) the regression model shows that the misallocation of land resources hinders the improvement of IGG in China; and (3) the decomposition of spatial spillover effects demonstrates that the misallocation of land resources has negative externalities, which will also have adverse effects on neighboring areas.
\end{abstract}

Keywords Inclusive green growth efficiency · Urban land resource $\cdot$ Resourcemisallocation $\cdot$ Spatial spillovereffect $\cdot$ China's land market

\section{Introduction}

With the continuous improvement of global industrialization and urbanization, the contradiction between economic development, social equity, and environmental protection has become increasingly prominent, bringing huge challenges to the sustainable development of the world. Over the past 20 years, economic growth has lifted 660 million people out of poverty and raised the income levels of millions of people, but growth has often come at the expense of the environment. In particular, developing countries are facing greater economic and environmental pressures. For a long time, several emerging

Responsible Editor: Eyup Dogan

Juntao Du

dujuntaohope@163.com

Qin $\mathrm{He}$

heqin16216@hunnu.edu.com

1 School of Public Administration, Hunan Normal University, Hunan 410081, People's Republic of China

2 School of Statistics and Applied Mathematics, Anhui University of Finance and Economics, Bengbu 233030, People's Republic of China economies have grown faster than developed countries, but the growth process requires a lot of resources, which may cause serious environmental damage (Ren et al. 2021; Dogan et al. 2021). At the same time, the problem of inequality is constantly increasing, which will bring great social risks. Although developing countries should focus on meeting basic needs and expanding growth opportunities, they do not need to achieve this goal at the cost of unsustainable environmental degradation (Yang et al. 2021).

The theme of the 2012 United Nations Conference on Sustainable Development (Rio+20) was "Green Economy in the Context of Sustainable Development and Poverty Eradication" and proposed inclusive green growth with the purpose of finding new sustainable development paths (Ali 2007). In the same year, the Word Bank released Inclusive Green Growth: The Pathway to Sustainable Development, proposing that the essence of inclusive green growth is to achieve economic, social, and environmental sustainability (Horwood 2005). Inclusive green growth (IGG) has become a new path of sustainable development and has attracted the attention of all countries. In 2012, the United Nations Environmental Programme (UNEP) developed the Green Economy Progress (GEP) framework to assess the level of inclusive green growth in various countries. In 2016, the 
United Nations New Sustainable Development Goals (SDGs) proposed a comprehensive approach to thoroughly address the three dimensions of social, economic, and environmental development. The concept of IGG, with the goal of eradicating poverty and protecting the environment, has attracted widespread attention from countries around the world.

But what is the IGG? How to measure the IGG? As the largest developing country and the largest carbon emission country, China's development level of IGG is our concern. This study attempts to define and measure the level of China's IGG and provide reference for the sustainable development of other countries in the world.

\section{Literature review}

In recent years, the research results on IGG have been enriched, but there is currently no unified method for measuring IGG (Adedoyin et al. 2020). Existing research believes that IGG should include two aspects: Inclusive growth and green growth. The United Nations Development Program (UNDP) believes that IGG includes fairness and inclusiveness in economic, social, and environmental aspects (Spratt and Griffith-Jones 2013). Albagoury believes that IGG emphasizes that, while economic growth can improve the welfare of present and future generations, IGG is more of a social welfare concept (Albagoury 2016). Bouma and Berkhout believe that IGG needs to take into account the greenness, inclusiveness, and welfare of economic growth (Berkhout et al. 2018). Therefore, when measuring IGG, more scholars have followed the methods of inclusive growth and green growth. Some scholars use methods such as the GDP per capita and income inequality, and other scholars use the generalized concentration curve and indifference curve (Aoyagi and Ganelli 2015; Oyinlola et al. 2020). Aoyagi and Ganelli use Gini coefficients and Bonferroni indices to measure the level of inclusive green growth (Aoyagi and Ganelli 2015). More scholars use the method of comprehensive indicators to conduct comprehensive evaluations based on SDGs. With the integration of the concepts of green growth and inclusive growth, some scholars have approached studies from the perspective of total factor productivity, taking income disparity and environmental pollution as undesirable products to build an index system for inclusive growth (Hu and Wang 2019). Sun et al. proposed a comprehensive directional distance function to evaluate the inclusive green growth (Sun et al. 2020).

Since the reform and opening up in 1978, China's economy has grown rapidly, becoming the second largest economy in the world. However, behind China's economic growth are huge energy consumption and pollution emissions, which have had a serious negative impact on China's environment (Song et al. 2018; Song et al. 2020). How to achieve sustainable development in China and coordinate the relationship between environmental pollution, energy consumption, and economic growth has always been the focus of academic research. The Chinese government is now aware that it is unsustainable to sacrifice the environment to obtain economic benefits and has actively worked to reduce pollutant emissions and protect the ecological environment (Hao et al. 2018; Shuai and Fan 2020; Wang et al. 2019a). The report of the 19th National Congress clearly stated that it is necessary to focus on the people, accelerate the construction of ecological civilization, promote green development, and highlight the sustainable development of society, the economy, and the environment. It can be said that transforming the economic development mode and realizing inclusive green growth have become the main goals of all sectors of Chinese society.

However, there is no general consensus on how to implement such a transformation in order to achieve green and inclusive growth (Adedoyin et al. 2020). Existing research is more focused on exploring the driving factors of IGG based on technological progress, poverty reduction, and environmental regulation (Du and Sun 2021; Song et al. 2021). However, there are a few studies that have been conducted from the perspective of resource allocation, especially research from the perspective of urban land resource allocation (Wang et al. 2019b). In the process of China's economic growth, China's unique land system has made great contributions to economic growth and industrial structure adjustment (Liu et al. 2018). Land transfer is an important part of the urban land system. The price and scale of land transfer are used to allocate different land resources to urban divisions and industrial sectors, so as to realize adjustments and upgrades of the industrial structure and ultimately have an impact on China's overall economy (Yang et al. 2019). China's urban land is owned by the state and has long relied on the government to allocate land (Liu et al. 2016). In 2001, China started the reform of land marketization and sold state-owned land through bidding, auctions, and listings. However, in the process of land market reform, local governments rely on increasing the price of residential and commercial land to obtain fiscal revenue and lower the price of industrial land to attract investment, resulting in a low land use efficiency and thus a misallocation of land resources (Lian et al. 2019; Xuemei et al. 2014).

The misallocation of land resources has led to an imbalance of the industrial structure, especially the pollution caused by the industrial structure dominated by heavy industry. Due to the decentralization system and promotion mechanism, the competition among regional governments for attracting investment has led to the spatial spillover effect of negative externalities in environmental pollution. Local governments attracting high-polluting enterprises for economic development will cause regional environmental pollution to become more serious. It is surprising that these crucial issues have not yet attracted widespread attention and investigations. To bridge the gaps in previous studies, we use EBM model to 
measure the level of China's IGG and analyze the impact of land misallocation on China's IGG, in order to provide reference for China or other countries that rely heavily on land finance to achieve sustainable development.

The main contributions of this research are as follows: (1) using the undesired EBM model and the MalmquistLuenberger (ML) index to incorporate economic growth, social equity, and ecological environment into the evaluation of China's inclusive green growth efficiency, providing new ideas for IGG measurement, and (2) analyzing the driving factors of IGG from the perspective of resource misallocation, providing a sustainable development idea for optimizing resource allocation for developing countries that lack element input.

\section{Methodology}

\section{Study area}

The research objects of this article are 30 provincial administrative units (provinces, autonomous regions, and municipalities) in Mainland China from 2009 to 2018. Hong Kong, Macau, Taiwan, and Tibet are not included due to a lack of data. According to the level of economic development and geographical distribution, Mainland China can be divided into three regions: the eastern, the central, and the western ${ }^{1}$. The economic development of the three regions presents a stepped characteristic. Among them, the economic development level of the eastern coastal areas is relatively high; the economic development level of the central region is lower than that of the eastern region, and the characteristics of labor-intensive industries are obvious. The ecological environment in the western region is relatively fragile, and the overall industrial level is lower than that in the eastern and central regions. All of the data were obtained from the China Statistical Yearbook and the Statistical Communique on National Economy and Social Development.

\section{Methods}

\section{Method for inclusive green growth}

Data envelopment analysis is currently one of the most important methods for efficiency estimation, especially the combination of the Malmquist index and data envelopment analysis, which can be employed to estimate the total factor

\footnotetext{
${ }^{1}$ The western includes Shaanxi, Sichuan, Yunnan, Guizhou, Guangxi, Gansu, Qinghai, Ningxia, Xinjiang, Inner Mongolia, and Chongqing. The Eastern China includes Hebei, Beijing, Tianjin, Shandong, Jiangsu, Shanghai, Zhejiang, Fujian, Guangdong, and Hainan. The central includes Shanxi, Henan, Anhui, Hubei, Jiangxi, and Hunan.
}

productivity (TFP) (Hidayati et al. 2017; Malmquist 1953; $\mathrm{Wu}$ et al. 2021). However, under the condition of a constant input, the total factor productivity obtained by combining the Malmquist index and the output-oriented directional distance function has a large deviation, and it is impossible to consider the bad output in economic operations, such as environmental pollution (Chambers et al. 1996; Mandal 2010). In order to overcome the problems of slack variables caused by the use of radial and directional Data Envelopment Analysis (DEA) to calculate the directional distance function, Chambers et al. proposed the Malmquist-Luenberger (ML) index, taking into account the input and output changes (Chambers et al. 1996). Oh further proposed the Global Malmquist-Luenberger (GML) index to solve the problem of undesired output changes (Oh 2010). This method avoids the unsolvable problems of the traditional ML index and circulating accumulation simultaneously.

Inclusive green growth (IGG) is an extension of the concept of green growth, which means that we should pay attention to ecological environment protection and social equity and justice while achieving economic growth. Therefore, EBM including environmental and social factors measures the inclusive green growth efficiency (IGGE). The EBM model measures the efficiency values based on comparable crosssections, and the efficiency values at different times are not comparable. In order to solve this problem, the Global Malmquist-Luenberger index is used for dynamic measurement based on the EBM model. GML is the dynamic change of inclusive green growth efficiency, so it is also called green total factor productivity (GTFP) (Song et al.,2018; Wu et al. 2020). This study uses GML as the measurement index of IGG.

When calculating the directional distance function of GML, this study adopted the EBM model. The EBM model was originally proposed by Tone and Tsutsui, combines the advantages of the traditional DEA model and the SBM model, and is compatible with radial and nonradial mixed distance functions (Tone and Tsutsui 2010). We defined the SuperEBM model and included the undesired outputs. The measurement formula is as follows:

$$
\begin{gathered}
r^{*}=\min \frac{\theta-\varepsilon \sum_{i=1}^{m} \frac{w_{i}^{-} s_{i}^{-}}{x_{i 0}}}{\phi+\varepsilon^{+}\left(\sum_{r=1}^{s} \frac{w_{r}^{+} s_{r}^{+}}{y_{i 0}}+\sum_{p=1}^{q} \frac{w_{p}^{z_{p}^{-}} s_{p}^{z^{-}}}{z_{p 0}}\right)} \\
\text { s.t. }\left\{\begin{array}{c}
\sum_{j}^{n} x_{i j} \lambda_{j}+s_{i}^{-}=\theta x_{i 0}, i=1,2, \cdots, m \\
\sum_{j}^{n} y_{r j} \lambda_{j}-s_{r}^{+}=\theta y_{i 0}, r=1,2, \cdots, s \\
\sum_{j}^{n} z_{i j} \lambda_{j}+s_{p}^{-}=\theta z_{i 0}, i=1,2, \cdots, q \\
\lambda_{j} \geq 0, s_{i}^{-}, s_{r}^{-}, s_{p}^{-} \geq 0
\end{array}\right.
\end{gathered}
$$

In Formula (1), $r^{*}$ represents the efficiency value of the EBM model, and $n$ is the number of decision-making units (DMUs). $x, y$, and $\mathrm{z}$ represent the inputs, desirable outputs, 
and undesirable outputs, respectively. $m, s$, and $q$ represent the numbers of inputs, desirable outputs, and undesirable outputs, respectively. $s_{r}^{+}$and $s_{p}^{-}$indicate the slack variable of desirable outputs and undesirable outputs, respectively. $w$ is the weight of the DMUs. $\lambda, \theta$, and $\varepsilon$ represent the parameters.
The dynamic changes in efficiency are further decomposed into changes in technological efficiency and changes in production technology to reflect changes in the production frontier.

$G M L_{t}^{t+1}=\left[\frac{1+\vec{D}_{0}^{t}\left(x^{t}, y^{t}, z^{t} ; y^{t},-z^{t}\right)}{1+\vec{D}_{0}^{t}\left(x^{t+1}, y^{t+1}, z^{t+1} ; y^{t+1},-z^{t+1}\right)} \times \frac{1+\vec{D}_{0}^{t+1}\left(x^{t}, y^{t}, z^{t} ; y^{t},-z^{t}\right)}{1+\vec{D}_{0}^{t}\left(x^{t+1}, y^{t+1}, z^{t+1} ; y^{t+1},-z^{t+1}\right)}\right]^{\frac{1}{2}}$

The ML index can further be decomposed into products of two components, which are the efficiency change $(\mathrm{GECH})$ and technology change $(\mathrm{GTCH})$ :

$G M L_{t}^{t+1}=G E C H_{t}^{t+1} \times G T C H_{t}^{t+1}$,

$\operatorname{GTCH}_{t}^{t+1}=\left[\frac{1+\vec{D}_{0}^{t+1}\left(x^{t}, y^{t}, z^{t} ; y^{t},-z^{t}\right)}{1+\vec{D}_{0}^{t}\left(x^{t}, y^{t}, z^{t} ; y^{t},-z^{t}\right)} \times \frac{1+\vec{D}_{0}^{t+1}\left(x^{t+1}, y^{t+1}, z^{t+1} ; y^{t+1},-z^{t+1}\right)}{1+\vec{D}_{0}^{t+1}\left(x^{t+1}, y^{t+1}, z^{t+1} ; y^{t+1},-z^{t+1}\right)}\right]^{\frac{1}{2}}$.

The $G E C H_{t}^{t, t+1}$ measures the change in relative efficiency between $t$ and $t+1$, and the $G T C H_{t}^{t+1}$ measures the shift in the frontier with the geometric mean of the technical change between $t$ and $t+1$ using input vectors from the two periods. These indexes indicate productivity improvements if their values are greater than one.

This study incorporated economic, social, and environmental factors into the IGG measurement framework, fully considering environmental pollution and social imbalances (Elhorst et al. 2013). IGG includes environmental protection and social equity in the process of economic growth. Inclusive growth should weigh efficiency and equity, and green growth should take into account both productivity improvement and environmental protection. Therefore, our input indicators mainly include factor inputs, including labor, capital, land, and energy. Desired output indicators include the economic growth, the growth of the industrial sector, and the increase in household consumption. The unemployment rate and environmental pollution discharge are regarded as undesired outputs (Table 1) (Ahmed 2012; Fowowe and Folarin 2019).

\section{Exploratory spatial data analysis}

This study used ESDA to analyze the spatial heterogeneity and spatial dependency of IGG. Spatial dependency analysis can be mainly divided into global spatial autocorrelation and local spatial autocorrelation analysis

$$
G E C H_{t}^{t, t+1}=\frac{1+\vec{D}_{0}^{G}\left(x^{t}, y^{t}, z^{t} ; y^{t},-z^{t}\right)}{1+\vec{D}_{0}^{G}\left(x^{t+1}, y^{t+1}, z^{t+1} ; y^{t+1},-z^{t+1}\right)},
$$

(Anselin and Cho 2002). Global spatial autocorrelation can be represented by Global Moran's I:

$\operatorname{Moran}^{\prime} s I=\frac{n \sum_{i=1}^{n} \sum_{j=1}^{n} w_{i j}\left(Y_{i}-\bar{Y}\right)\left(Y_{j}-\bar{Y}\right)}{\sum_{i=1}^{n}\left(Y_{i}-\bar{Y}\right)^{2} \sum_{i=1}^{n} \sum_{j=i}^{n} w_{i j}}$.

Here, $Y_{i}$ is the observation value of the $\mathrm{i}$-th province, and $\bar{Y}$ is the sample mean. The spatial weight matrix $w_{i j}$ is constructed by a reciprocal of the geographical distance:

$w_{i j}=\left\{\begin{array}{l}\frac{1}{d_{i j}}, i \neq j, i, j=1,2, \cdots, n \\ 0, i=j\end{array}\right.$

The $d_{i j}$ is the geographical distance between the $\mathrm{i}$-th and $\mathrm{j}$ th province. This study used the latitude and longitude of the capital city to calculate the distance between provinces.

$Z_{I}=\frac{I-E[I]}{\sqrt{V[I]}}$

Among them,

$E[I]=-\frac{1}{n-1}$,

$V[I]=E\left[I^{2}\right]-E[I]^{2}$. 
Table 1 Input and output indicators for the inclusive green growth efficiency (IGGE).

\begin{tabular}{lll}
\hline Indicator type & Indicator & Indicator description \\
Input & Labor input & Employment in secondary and tertiary industries \\
& Capital input & Investment in fixed assets \\
& Land resource input & Measured by built-up area of each province \\
& Energy input & Measured by the total energy consumption of each province \\
Desirable output & Economic output & Gross regional product (GRP) \\
& Social output & Urban and rural residents' consumption ratio \\
& Industry output & The value of the output of secondary and tertiary industries \\
Undesirable output & Social output & Unemployment rate \\
& Environment output & Industrial wastewater discharge, industrial waste gas emissions, and industrial solid waste production \\
\hline
\end{tabular}

Note: Since the EBM model measures the relative efficiency, capital depreciation does not have much of an impact on the relative ranking, and the results obtained by different depreciation rates are different, so this article does not depreciate capital. The calculation of the IGG of each province is based on the MAXDEA Pro software.

Local spatial autocorrelation analysis measures and statistically tests the indicators of local indications of spatial association (LISA). The local Moran's I can be calculated using the following formula:

$$
I_{i}=\frac{n \sum_{i=1}^{n} \sum_{j=1}^{n} w_{i j}\left(Y_{i}-\bar{Y}\right)\left(Y_{j}-\bar{Y}\right)}{\sum_{i=1}^{n}\left(Y_{i}-\bar{Y}\right)^{2}} .
$$

\section{Regression model}

This study hypothesized that the misallocation of land resources, as a kind of element misallocation, can have an impact on the economic structure and pollution emissions, thereby affecting the level of IGG. Therefore, a basic regression model of land resource misallocation (LMA) affecting IGG was established.

$I G G_{i t}=\alpha+\beta_{0} L M A_{i t}+\beta_{j}$ Contral $_{i t}+\varepsilon_{i t}$,

where $i$ and $t$ are time and individual effects, respectively, which refer to 30 provinces in China from 2009 to 2018. $\alpha$ is the intercept term, and $\beta$ is the estimated coefficient of the model. Contral ${ }_{i t}$ represents the control variables, indicating other variables that can affect IGG, and $\varepsilon_{i t}$ represents the random error terms.

Model (13) has static panel data, but existing research points out that the individual behavior of economic variables is affected by past behavior; that is, IGG is a process of dynamic development and accumulation. Therefore, we inserted the lag term of the explained variable IGG into the model to obtain Model (14)

$$
I G G_{i t}=\alpha+\eta I G G_{i, t-1}+\beta_{0} L L M A_{i t}+\beta_{j} \text { Contral }_{i t}+\varepsilon_{i t} .
$$

The dynamic panel model has an endogenous problem caused by the reciprocal causation of variables and missing variables. In order to solve this problem, we used the system generalized method of moments (SYS-GMM) with the lagged variables in the model as instrumental variables. Furthermore, combined with ESDA, this study hypothesized that the misallocation of land resources affects IGG and has a spatial correlation, so Model (14) was added to the spatial weight matrix and extended to the spatial dynamic panel model (Elhorst et al. 2013; Lee and Yu 2010).

$$
\begin{gathered}
I G G_{i t}=\alpha+\eta I G G_{i, t-1}+\eta w_{i j} I G G_{i, t}+\eta w_{i j} I G G_{i, t-1} \\
+\beta_{0} L M A_{i t}+\beta_{j} \text { Contral }_{i t}+\varepsilon_{i t}
\end{gathered}
$$

Land misallocation (LMA) refers to the difference in the marginal output of land with different uses, but China lacks micro-data corresponding to land at this stage. Considering that China's land use is sold according to the land use determined by the land plan, the land market for different uses is segmented. The most important one is the difference between residential land and industrial land. Therefore, this study used the ratio of residential land transfer price to industrial land transfer price to indicate the degree of land misallocation. In order to obtain a more robust estimation result, it employed both residential land and industrial land newly transferred areas, and the agreement transfer land area was compared with the total transfer area as a robustness index to test the misallocation of land resources.

The control variables selected in this study mainly include the technology level (RD), expressed as the proportion of regional research and development expenditure in GDP (Cao et al. 2021); the education level of residents (Edu), which is expressed in terms of per capita years of education (Zhou et al. 2020); the direct use of foreign direct investment (FDI), which is expressed by the proportion of FDI in GDP (Jin et al. 2021); the degree of openness (Open), which is expressed by the proportion of total import and export trade in GDP (Jin et al. 
2021); the urbanization level (Urban), which is expressed as the proportion of urban population; the level of local economic development, which is expressed by GDP per capita (Gdpc) (Zhou et al. 2021); and the environmental regulation level (ER), which was selected to control the impact of environmental governance on IGGR, expressed by the comprehensive utilization rate of industrial solid waste. The descriptive statistics of variables are shown in Table 2.

\section{Results}

\section{The temporal-spatial characteristics of IGG}

Fig. 1 shows the basic situation of IGG in China from 2009 to 2018. It can be seen that, in 2009, the IGG level in most regions of China was between 0.7 and 1.5 , and the IGG in the central and western regions exhibited spatial clustering. Except for Ningbo, Shandong, and Guangdong in 2012, the IGG level of most regions in China exceeded 1, and the overall level was between 1 and 1.5. In 2015, the IGG level in the Jiangxi area rose, but that in Xinjiang fell to the 0.7-1 range. In 2018 , the number of regions with IGG exceeding 1.5 reached 13 provinces, and all regions except Guangdong had IGG values exceeding 1 . This shows that China's IGG level basically displayed an upward trend from 2009 to 2018, and regions with the same IGG level exhibited obvious spatial agglomeration characteristics.

According to Fig. 1, China's IGG level shows an obvious spatial correlation. Therefore, this study introduced Moran's I to test the spatial correlation of IGG from 2009 to 2018, as shown in Fig. 3. According to Fig. 2, in 2009-2018, the IGG between Chinese provinces showed a positive spatial correlation, with Moran's I ranging from 0.119 to 0.135 . China's IGG has obvious phase characteristics. The spatial correlation degree of IGG in the three phases of 2010-2012, 2013-2015, and 2016-2017 exhibited a clear upward trend. However, from 2015 to 2018, the IGG level of each province began to

Table 2 Descriptive statistics of regression variables.

\begin{tabular}{llllll}
\hline Variable & Obs & Mean & Std. Dev. & Min & Max \\
\hline IGG & N:30, T:10 & 1.2178 & 0.249 & 0.7100 & 2.2225 \\
LMA & N:30, T:10 & 0.6019 & 0.5924 & 0.0200 & 6.4149 \\
RD & N:30, T:10 & 0.0145 & 0.0105 & 0.0021 & 0.0601 \\
Edu & N:30, T:10 & 8.7961 & 0.946 & 6.7639 & 12.3891 \\
FDI & N:30, T:10 & 0.0231 & 0.0203 & 0.0000 & 0.1563 \\
Open & N:30, T:10 & 0.3173 & 0.3914 & 0.0284 & 1.8910 \\
Urban & $\mathrm{N}: 30, \mathrm{~T}: 10$ & 0.5354 & 0.1356 & 0.2825 & 0.8961 \\
Gdpc & $\mathrm{N}: 30, \mathrm{~T}: 10$ & 2.7759 & 1.5455 & 0.5812 & 8.5954 \\
ER & $\mathrm{N}: 30, \mathrm{~T}: 10$ & 0.0096 & 0.0021 & 0.0042 & 0.0182 \\
\hline
\end{tabular}

fluctuate, which was mainly caused by competition for investment and political promotion among Chinese local governments.

Fig. 3 shows the local Moran value distribution of China's IGG level in some years. The first quadrant $\mathrm{HH}$ represents the spatial connection form in which the area unit with a high observation value is surrounded by the area with a high value. The second quadrant LH represents the spatial connection form in which the area unit with a low observation value is surrounded by the area with a high value. The third quadrant LL represents the spatial connection form in which the area unit with a low observation value is surrounded by the area with a low value. The fourth quadrant HL represents the spatial connection form in which the area unit with a high observation value is surrounded by the area with a low value. The important advantage of the Moran scatter plot is that it is able to specifically distinguish between the high value and high value, low value and low value, high value and low value, and low value and high value between the regional unit and its neighbors. When comparing Fig. 1 and Fig. 2, it is not difficult to find that, in 2009, the distribution of IGG in China was relatively concentrated, and the IGG difference between neighboring regions was small. In 2012 and 2015, most regions were concentrated in the HH and LL regions, indicating that the IGG levels in neighboring regions during this period displayed obvious agglomeration characteristics. The distribution of the four quadrants in 2018 is relatively balanced, and the differences between regions have further expanded.

\section{Regression model results}

The estimation results of land resource misallocation affecting IGG are shown in Table 3. The first two columns are the GMM estimation results of non-spatial panels, and the third and fourth columns are SDM results estimated by GMM, respectively. The estimation results of AR (1) and AR (2) show that the random disturbance term has first-order serial autocorrelation, but not second-order serial autocorrelation. The Sargen test cannot reject the null hypothesis that "there is no over-identification (all instrumental variables are valid)". It shows that the dynamic GMM estimation result is robust.

It can be seen from Table 3 that the row coefficient where the lag coefficient of IGG is located is positive and significant at the $1 \%$ statistical level; that is, the development of IGG in the previous period has a significant positive impact on its value in the current period. This shows that IGG's promotion is a long-term accumulation and development process. Areas with higher IGG levels in the early stage may achieve higher levels at this stage. The Spatial Rho coefficient is positive, and the significance test is significant, which is consistent with the ESDA test, proving that the impact of land resource misallocation with IGG is spatially correlated. 


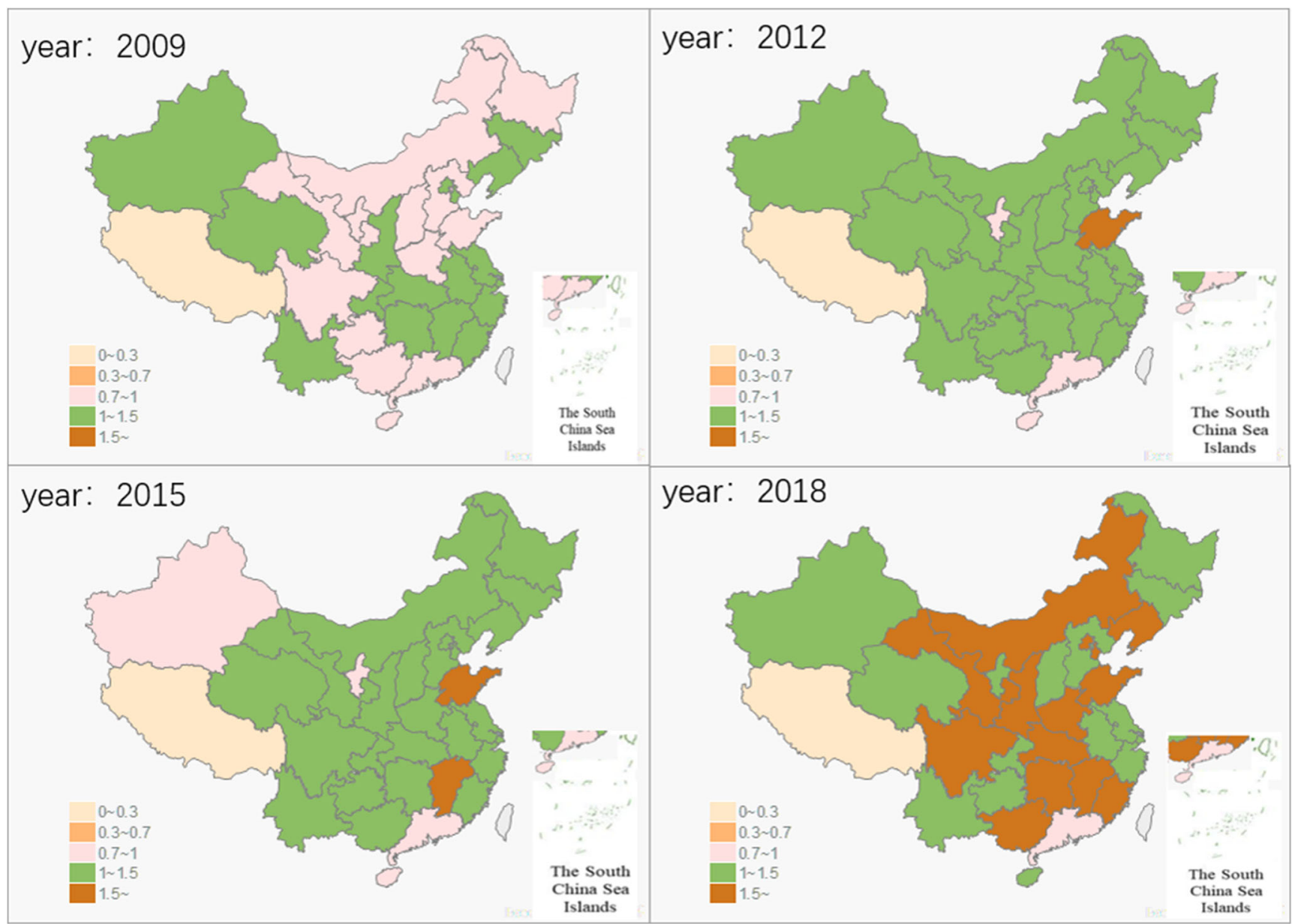

Fig. 1 The trend of IGG from 2009 to 2018. Note: The picture is from the author's calculation.

The coefficient of LMA is significantly negative, indicating that the misallocation of urban land resources in China hinders the improvement of IGG. As China's local governments are more inclined to use lower industrial land prices to attract industrial investment, and to increase commercial and housing prices to obtain fiscal revenue, this will lead to misallocations in land prices and land areas for different uses, increase production costs, and backlog R\&D investment. Although the misallocation of land resources increases local fiscal revenue in the short term, it reduces the marginal output of land and is ultimately detrimental to economic growth. In particular, in order to achieve economic growth, some regions ignore environmental protection and reduce industrial land prices to attract investment. This has led to the agglomeration of high-polluting enterprises and further hindered the improvement of IGG.

\section{Spatial spillover effect}

Table 4 reports the estimated results of direct effects, indirect effects (spatial spillover effects), and total effects of the spatial model. The short-term effects of the misallocation of land resources have all passed the significance test. Due to the feedback effect of the spatial effect, the coefficient of the short-term direct effect of land resource misallocation is different from the coefficient in the fourth column of Table 3 of the model. The short-term spatial spillover effect of the misallocation of land resources is significantly negative, indicating that the misallocation of land resources is not only detrimental to the improvement of IGG in the region, but also adversely affects the IGG in neighboring areas. From the perspective of long-term effects, the misallocation of land resources has a more significant negative impact on IGG in the region, and the coefficient of long-term spatial spillover effects is not significant.

From the perspective of the spatial spillover effect and total effect of the control variables, RD has a short-term positive spillover effect on IGG in neighboring areas, and its short-term and long-term total effects are both positive, indicating that $\mathrm{RD}$ is an important factor in the improvement of the IGG level. Strengthened RD investment can effectively promote the improvement of IGG. The shortterm effects of residents' education level (Edu) are all 
Fig. 2 The value of global Moran's I.

significantly positive, indicating that the improvement of residents' education level will promote the growth of IGG in this region and neighboring areas, and the flow of talent will enhance the overall IGG of the region. The spillover effect of the direct use of foreign direct investment is negative, passing the $10 \%$ significant test, which shows that the use of FDI in China has led to the agglomeration of polluting companies, forming "pollution refuges," which will adversely affect IGG in neighboring areas. The level of urbanization (Urabn) has a positive impact on IGG. However, the level of opening to the outside world (Open) is not conducive to the improvement of
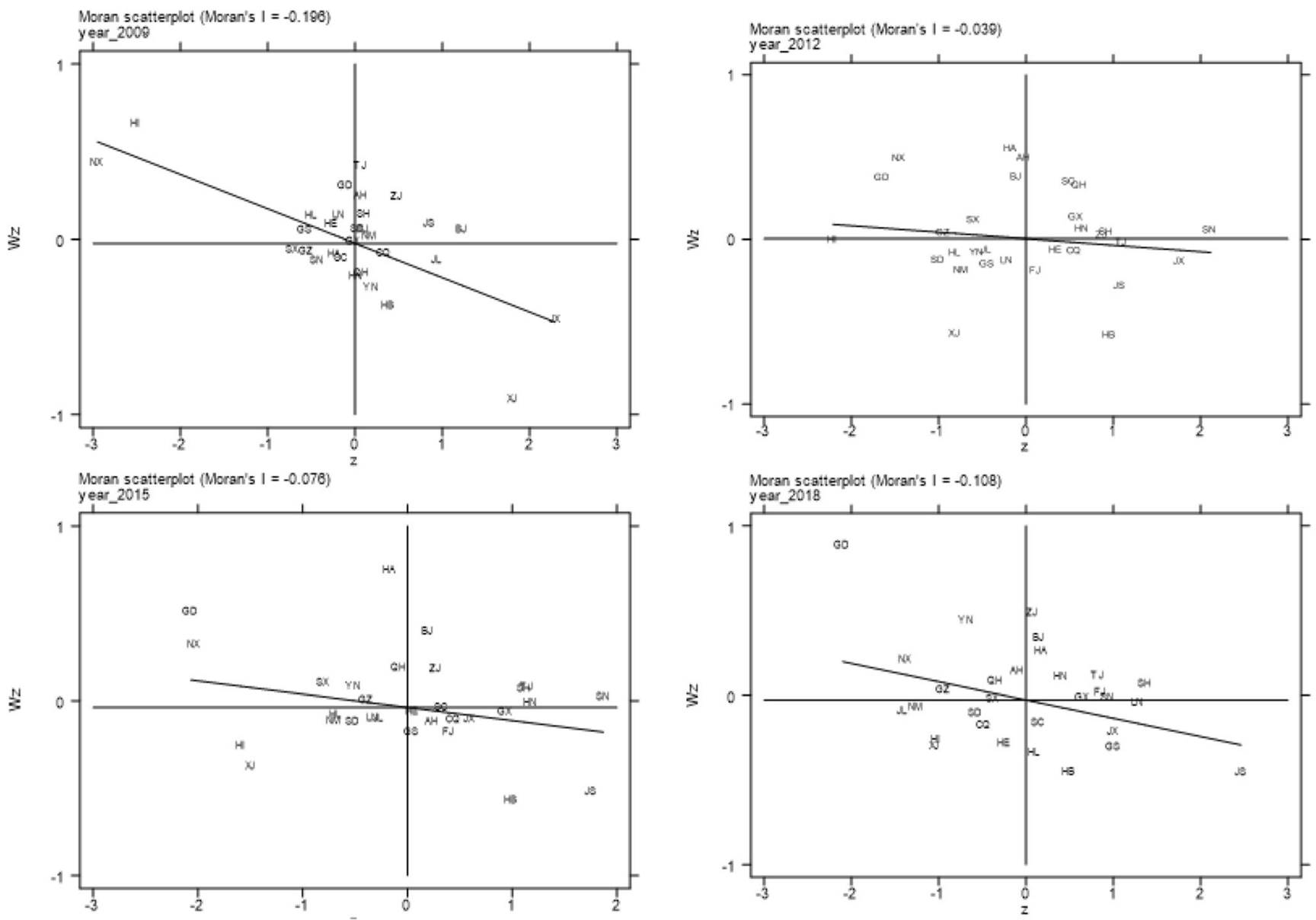

Fig. 3 Local Moran's I value. 
Table 3 regression model results.

\begin{tabular}{|c|c|c|c|c|}
\hline Variable & GMM & GMM & SDM & SDM \\
\hline L.IGG & $1.0093 * * *(10.36)$ & $0.6637 * * *(18.76)$ & $0.9701 * * *(21.65)$ & $0.9566^{* * *}(20.69)$ \\
\hline LMA & $-0.0026 * * *(3.91)$ & $-0.0394 * * *(-3.35)$ & $-0.0028 * *(-2.02)$ & $-0.0020 *(1.85)$ \\
\hline $\mathrm{Rd}$ & & $19.2390 * * *(6.20)$ & & $6.2188 * *(2.49)$ \\
\hline Edu & & $0.0782 * * *(7.70)$ & & $0.0378(1.49)$ \\
\hline FDI & & $3.1769 * * *(3.09)$ & & $3.1180 * * *(3.00)$ \\
\hline Open & & $-0.3962 * * *(-3.99)$ & & $-0.1260 *(-1.73)$ \\
\hline Urban & & $-2.2121(-0.28)$ & & $0.1262 * * *(2.99)$ \\
\hline Gdpc & & $0.0932 * *(2.35)$ & & $-0.0234(-1.00)$ \\
\hline $\mathrm{Er}$ & & $-24.0303 * * *(-4.71)$ & & $0.6599(0.18)$ \\
\hline Constant & $0.0389 * * *(3.54)$ & $1.0007 * * *(3.15)$ & $0.0065 * * *(12.86)$ & $0.0059 * * *(12.90)$ \\
\hline AR (1) & $-1.85 *[0.065]$ & $-1.98 * *[0.048]$ & $-1.72 *[0.085]$ & $-1.82 *[0.069]$ \\
\hline $\operatorname{AR}(2)$ & $-0.60[0.552]$ & $-0.69[0.491]$ & $-0.77[0.441]$ & $-0.95[0.341]$ \\
\hline Sargen test & $28.76[0.799]$ & $25.81[0.214]$ & $23.03[0.775]$ & $29.81[0.757]$ \\
\hline Spatial Rho & & & $0.4771 * * *(5.65)$ & $0.2361 * *(2.16)$ \\
\hline W* L1. IGG & & & $-0.3848 * * *(-3.68)$ & $-0.8054 * * *(-5.20)$ \\
\hline $\mathrm{W}^{*}$ Land & & & $-0.1406^{* *}(-2.50)$ & $-0.0079 * *(2.10)$ \\
\hline $\mathrm{W}^{*} \mathrm{Rd}$ & & & & $13.3774(0.68)$ \\
\hline $\mathrm{W}^{*} \mathrm{Edu}$ & & & & $-0.0459 *(-1.87)$ \\
\hline W*FDI & & & & $0.9593(0.14)$ \\
\hline $\mathrm{W}^{*}$ Open & & & & $-0.4598 * *(-1.98)$ \\
\hline $\mathrm{W}^{*}$ Urban & & & & $0.2147(0.14)$ \\
\hline $\mathrm{W}^{*} \mathrm{Gdpc}$ & & & & $0.2059 * * *(2.99)$ \\
\hline $\mathrm{W}^{*} \mathrm{Er}$ & & & & $-23.8548(-1.43)$ \\
\hline
\end{tabular}

Note: ***,**, and * are significant at the levels of $1 \%, 5 \%$, and $10 \%$, respectively; () is the $T$ value; and [] is the $P$ value.

the IGG level in the short term, which has adverse effects on the region and neighboring areas, and the total effect in the short and long term is negative. The regional economic development level (Gdpc) short-term spillover effect and short-term total effect are positive, indicating that regions with higher economic development levels have a positive effect on the improvement of IGG in neighboring areas.

\section{Robustness test}

In order to get robust estimation results, we test the regression results of the relationship between LMA and IGG, and the results are shown in Table 5.

According to Table 5, first of all, based on the decomposition of GML, we regress MECH and METH as explained variables (Model (1) and Model (2)). The results show that

Table 4 Direct and indirect marginal effects.

\begin{tabular}{|c|c|c|c|c|c|c|}
\hline \multirow[t]{2}{*}{ Variable } & \multicolumn{3}{|l|}{ Short-term effects } & \multicolumn{3}{|l|}{ Long-term effects } \\
\hline & Direct & Indirect & Total & Direct & Indirect & Total \\
\hline LMA & $-0.0006 * *(-2.05)$ & $-0.0068 * *(-2.06)$ & $-0.0074 * *(-2.06)$ & $-0.2113 * *(-2.10)$ & $0.2036(0.10)$ & $-0.0078(-0.06)$ \\
\hline $\mathrm{Rd}$ & $6.4476 *(1.90)$ & $16.9711 *(1.72)$ & $23.4188 *(-1.88)$ & $31.2318(1.02)$ & $-1.8738(-1.00)$ & $29.3580 *(1.87)$ \\
\hline Edu & $0.0389 * *(2.32)$ & $0.0729 * *(2.22)$ & $0.1118^{* *}(1.96)$ & $0.5627(1.04)$ & $-0.4223(-1.03)$ & $0.1404 *(1.92)$ \\
\hline FDI & $3.0612 * * *(2.86)$ & $-0.9206 * *(-2.09)$ & $-2.1406(0.21)$ & $-16.2501(-1.02)$ & $13.4975(0.98)$ & $-2.7526(-1.21)$ \\
\hline Open & $-0.1323 *(-1.73)$ & $-0.6195 * *(-2.40)$ & $-0.7519 * * *(2.70)$ & $-0.9691(-1.03)$ & $0.0282(1.00)$ & $-0.9409 * * *(-2.68)$ \\
\hline Urban & $0.1173 * *(2.26)$ & $0.4051 * *(2.20)$ & $0.5224 * *(2.26)$ & $4.3418(1.05)$ & $-3.7190(1.04)$ & $0.6229(1.24)$ \\
\hline Gdpc & $-0.0183(-0.81)$ & $0.2567 * * *(2.81)$ & $0.2383 * * *(2.70)$ & $0.2077(1.02)$ & $0.0927(1.01)$ & $0.3004 * *(2.55)$ \\
\hline $\mathrm{Er}$ & $0.3331(0.09)$ & $-33.1448(-1.55)$ & $-32.8112(-1.47)$ & $-25.0183(-1.03)$ & $-16.1969(-1.02)$ & $-41.2152(-1.42)$ \\
\hline
\end{tabular}

Note: ***,**, and * are significant at the levels of $1 \%, 5 \%$, and $10 \%$, respectively; () is the $T$ value. 
Table 5 Robustness Test

\begin{tabular}{lllll}
\hline Variable & $(1)$ & $(2)$ & $(3)$ & $(4)$ \\
& GECH & GTCH & IGG & IGG \\
LMA & $-0.0011 * *(-2.03)$ & $-0.0666^{* *}(-2.34)$ & $-0.1145 * *(-2.08)$ & \\
LMA_Area & & & & $-0.0363 * *(-2.05)$ \\
Rd & $-0.7659(-0.99)$ & $1.4974 * * *(2.77)$ & $-3.8677(-0.97)$ & $-4.7259(-1.15)$ \\
Edu & $-0.0002(-0.02)$ & $0.0137(1.54)$ & $-0.0103 * *(-2.25)$ & $-0.0230(-0.72)$ \\
FDI & $0.0856(0.34)$ & $0.0794(0.45)$ & $1.4741^{*}(1.87)$ & $1.2245(1.55)$ \\
Open & $0.0178(0.80)$ & $-0.0516^{* * *(-3.32)}$ & $-0.1203 *(-1.67)$ & $-0.0960(-1.35)$ \\
Urban & $0.0337(0.29)$ & $-0.1034(-1.26)$ & $0.4723(1.08)$ & $0.6155(1.38)$ \\
Gdpc & $-0.0047(-0.60)$ & $1.3132 * * *(0.70)$ & $0.0561 * *(2.34)$ & $0.0617 * *(2.45)$ \\
Er & $-4.5512 *(1.68)$ & $0.5433^{* * *}(2.71)$ & $-1.3142(-0.25)$ & $-3.2202(-0.62)$ \\
Spatial Rho & $0.3749 * * *(3.31)$ & $0.5930^{* * *}(6.70)$ & $0.1833^{* *}(2.20)$ & $0.1780 * *(2.16)$ \\
\hline
\end{tabular}

Note: ***,**, and * are significant at the levels of $1 \%, 5 \%$, and $10 \%$, respectively; () is the $T$ value.

there is a negative correlation between LMA and METC and METH at 5\% significance level. It shows that LMA affects IGG from two aspects of efficiency change (GECH) and technology change (GTCH), which is basically consistent with the conclusion of benchmark regression.

Furthermore, a 0-1 spatial weight matrix is used to replace $\mathrm{w}_{\mathrm{ij}}$, and the estimation results of model 3 in Table 5 are obtained. Found that the homogeneity estimation results can still be obtained by changing the spatial weight matrix. Spatial Rho shows that the spatial regression relationship still exists.

Finally, by changing the core explanatory variable and replacing the LMA represented by the ratio of land price with the LMA_Area represented by the ratio of land area, the consistent regression results can still be obtained, which proves the robustness of the estimation results.

\section{Conclusion and policy implications}

\section{Conclusion}

Over the years, China has taken GDP as an important goal of economic growth, which has led to income gaps and environmental pollution, exerting great pressure on China's sustainable development. With the continuous improvement of the level of economic development, China has begun to transform its economic growth mode to achieve inclusive green growth as an important goal of sustainable development. Based on this topic, this study used a combination of the EBM model and ML index to measure China's IGG at the provincial level from 2009 to 2018 and incorporated economic growth, environmental protection, and social equity into the unified framework of IGG. It analyzed the impact on IGG from the perspective of the misallocation of land resources and considered the spatial interaction caused by regional competition.

Studies have shown that China's IGG level has continued to increase in recent years. In 2009, more than half of China's provinces had IGG levels below 1, and no province exceeded 1.5. However, by 2018, the IGG level of most provinces in China exceeded 1 , and even one-third of the provinces reached a high level of 1.5. At the same time, the distribution of IGG is characterized by obvious spatial agglomeration, and the agglomeration level of IGG in neighboring provinces is continuously improving. From the regression results, we can conclude that the misallocation of land resources does hinder the improvement of China's IGG level. China has achieved rapid economic growth by relying on land finance, but the long-term unbalanced land planning has also hindered China's sustainable development. The estimation of the spatial regression model shows that the misallocation of land resources has spatial spillover effects. Driven by factors such as local competition and the flow of factors, the misallocation of land resources not only adversely affects the IGG in the region, but may also damage the improvement of IGG in neighboring regions.

\section{Policy implications}

At present, IGG is a feasible way of sustainable development. In particularly, developing countries are faced with three pressures from economic growth, social equity, and environmental protection and need to play to their comparative advantages and find effective ways to improve IGG. For developing countries, government departments play a leading role in economic operations. The government's control of industrial and commercial land can easily lead to the misallocation of land resources and reduce the marginal output of land resources. This will adversely affect the long-term economic growth and environmental protection of the region. Relying on the development path of lowering industrial land prices to attract investment will lead to the agglomeration of high-polluting enterprises and cause the economy to be locked in an unsustainable growth path. Compared with ways to increase IGG, such as increasing investment and technological innovation, it is 
easier to adjust the structure of factor allocation to exploit the comparative advantages of developing countries. At the same time, this study verifies that the misallocation of land resources will hinder the improvement of IGG. Therefore, it is necessary to promote the reform of land marketization, optimize the structure of the land supply, break the monopoly of local governments over land resources, and further exert the basic role of the market in resource allocation. In particularly, IGG exhibits obvious spatial agglomeration and spatial spillover effects. Regional cooperation should be carried out to allow regions with higher IGG levels to have a leading role in low-efficiency regions.

\section{Limitations and outlook}

Although this study used China's provincial data from 2009 to 2018 to obtain sufficient conclusions, the provincial data ignore internal differences, and there are large errors in both the estimation of IGG and the measurement of the mismatch level of land resources. In particular, due to the inability to obtain micro data on the marginal output of land, we could only obtain indicators of land resource mismatch by indirect measurement methods. In future research, we will pay more attention to the impact of the misallocation of land resources on the sustainable development of enterprises and industries and explore new paths for the sustainable development of the economy, society, and the environment. In addition, due to the impact of COVID-19, the world's major economies began to enter the stage of steady growth or degrowth. Inclusive and green growth gradually replaces the status of growth in economic operation. How to define IGG and change the mode of global economic development is a new challenge facing mankind.

Author contribution All authors contributed to the scientific content and authorship of this manuscript. Conceptualization, Qin $\mathrm{He}$ and Juntao Du; data curation, Qin He; methodology, Juntao Du; writing (original draft), Juntao Du; and writing (review and editing), Juntao $\mathrm{Du}$

Funding This work was supported by the Major Programs of National Fund of Philosophy and Social Science of China (Grant No. 20ZDA084).

Data Availability The datasets used and/or analyzed during the current study are available from the corresponding author on reasonable request.

\section{Declarations}

Ethics approval and consent to participate Not applicable.

Consent for publication Not applicable.

Competing interests The authors declare no competing interests.

\section{References}

Adedoyin FF, Bekun FV, Driha OM, Balsalobre-Lorente D (2020) The effects of air transportation, energy, ICT and FDI on economic growth in the industry 4.0 era: Evidence from the United States. Technol Forecast Soc Chang 160:120297

Ahmed EM (2012) Green TFP intensity impact on sustainable East Asian productivity growth. Economic Analysis \& Policy 42(1):67-78

Albagoury, S. (2016). Inclusive green growth in Africa: Ethiopia case study. Retrieved from: https://mpra.ub.unimuenchen.de/id/eprint/ 74364.MPRA, Paper No. 74364

Ali I (2007) Inequality and the Imperative for Inclusive Growth in Asia. Asian Dev Rev 24(2):1-16

Anselin L, Cho WKT (2002) Spatial effects and ecological inference. Polit Anal 10:276-297

Aoyagi C, Ganelli G (2015) Asia's quest for inclusive growth revisited. J Asian Econ 40:29-46

Berkhout E, Bouma J, Terzidis N, Voors M (2018) Supporting local institutions for inclusive green growth: developing an Evidence Gap Map. NJAS-Wageningen Journal of Life Sciences 84:51-71

Cao J, Law SH, Samad ARBA, Mohamad WNBW, Wang J, Yang X (2021) Impact of financial development and technological innovation on the volatility of green growth-evidence from China. Environ Sci Pollut Res 1-17. https://doi.org/10.1007/s11356-02113828-3

Chambers RG, Chung Y, Färe R (1996) Benefit and distance functions. J Econ Theory 70(2):407-419

Dogan E, Inglesi-Lotz R, Altinoz B (2021) Examining the determinants of renewable energy deployment: does the choice of indicator matter? Int J Energy Res 45(6):8780-8793. Retrieved from. https://doi. org/10.1002/er.6413

Du J, Sun Y (2021) The nonlinear impact of fiscal decentralization on carbon emissions: from the perspective of biased technological progress. Environ Sci Pollut Res 28:29890-29899. https://doi.org/ 10.1007/s11356-021-12833-w

Elhorst P, Zandberg E, De Haan J (2013) The impact of interaction effects among neighbouring countries on financial liberalization and reform: a dynamic spatial panel data approach. Spat Econ Anal 8(3): 293-313

Fowowe B, Folarin EO (2019) The effects of fragility and financial inequalities on inclusive growth in African countries. Rev Dev Econ 23(3):1141-1176

Hao Y, Deng Y, Lu Z-N, Chen H (2018) Is environmental regulation effective in China? Evidence from city-level panel data. J Clean Prod 188:966-976

Hidayati N, Siregar H, Pasaribu SH (2017) Determinant of efficiency of the Islamic banking in Indonesia. Buletin Ekonomi Moneter dan Perbankan 20(1):29-48

Horwood R (2005) The pathway to sustainable resource management. Process Saf Environ Prot 83(6):504-508

$\mathrm{Hu}$ W, Wang R (2019) Which Chinese cities are more inclusive and why? Cities 86:51-61

Jin G, Yu B, Shen K (2021) Domestic trade and energy productivity in China: an inverted U-shaped relationship. Energy Econ 97:105234

Lee L-F, Yu J (2010) A spatial dynamic panel data model with both time and individual fixed effects. Econometric Theory 26(2):564-597

Lian H, Li H, Ko K (2019) Market-led transactions and illegal land use: evidence from China. Land Use Policy 84:12-20

Liu T, Cao G, Yan Y, Wang RY (2016) Urban land marketization in China: central policy, local initiative, and market mechanism. Land Use Policy 57:265-276

Liu Y, Li J, Yang Y (2018) Strategic adjustment of land use policy under the economic transformation. Land Use Policy 74:5-14

Malmquist S (1953) Index numbers and indifference surfaces. Trab Estad 4(2):209-242 
Mandal SK (2010) Do undesirable output and environmental regulation matter in energy efficiency analysis? Evidence from Indian cement industry. Energy Policy 38(10):6076-6083

Oh D-h (2010) A global Malmquist-Luenberger productivity index. J Prod Anal 34(3):183-197

Oyinlola MA, Adedeji AA, Bolarinwa MO, Olabisi N (2020) Governance, domestic resource mobilization, and inclusive growth in sub-Saharan Africa. Economic Analysis and Policy 65:68-88

Ren S, Hao Y, Xu L, Wu H, Ba N (2021) Digitalization and energy: how does internet development affect China's energy consumption? Energy Econ 98:105220

Shuai S, Fan Z (2020) Modeling the role of environmental regulations in regional green economy efficiency of China: empirical evidence from super efficiency DEA-Tobit model. J Environ Manag 261: 110227

Song M, Du J, Tan KH (2018) Impact of fiscal decentralization on green total factor productivity. Int J Prod Econ 205:359-367. https://doi. org/10.1016/j.ijpe.2018.09.019

Song M, Shuai Z, Jianlin W, Jiajia Z (2020) Share green growth: regional evaluation of green output performance in China. Int J Prod Econ 219:152-163. https://doi.org/10.1016/j.ijpe.2019.05.012

Song M, Xie Q, Wang S, Zhou L, \& Lev B. (2021). Intensity of environmental regulation and environmentally biased technology in the employment market

Spratt S, \& Griffith-Jones S (2013). Mobilising investment for inclusive green growth in low-income countries: Deutsche Gesellschaft für Internationale Zusammenarbeit (GIZ) $\mathrm{GmbH}$

Sun Y, Ding W, Yang Z, Yang G, Du J (2020) Measuring China's regional inclusive green growth. Sci Total Environ 713:136367. https://doi.org/10.1016/j.scitotenv.2019.136367

Tone K, Tsutsui M (2010) An epsilon-based measure of efficiency in DEA-a third pole of technical efficiency. Eur J Oper Res 207(3): $1554-1563$
Wang S, Shi C, Fang C, Feng K (2019a) Examining the spatial variations of determinants of energy-related $\mathrm{CO} 2$ emissions in China at the city level using Geographically Weighted Regression Model. Appl Energy 235:95-105

Wang S, Sun X, Song M (2019b) Environmental regulation, resource misallocation, and ecological efficiency. Emerg Mark Financ Trade: $1-20$

Wu H, Hao Y, Ren S (2020) How do environmental regulation and environmental decentralization affect green total factor energy efficiency: evidence from China. Energy Econ 91:104880

Wu H, Hao Y, Ren S, Yang X, Xie G (2021) Does internet development improve green total factor energy efficiency? Evidence from China. Energy Policy 153:112247

Xuemei B, Peijun S, Yansui L (2014) Realizing China's urban dream. Nature 509(1799):158-160

Yang Y, Jiang G, Qiuyue Z, Zhou D, Yuling L (2019) Does the land use structure change conform to the evolution law of industrial structure? An empirical study of Anhui Province, China. Land use policy: The International Journal Covering All Aspects of Land Use 81: 657-667

Yang X, Wu H, Ren S, Ran Q, Zhang J (2021) Does the development of the internet contribute to air pollution control in China? Mechanism discussion and empirical test. Struct Chang Econ Dyn 56:207-224

Zhou X, Xia M, Zhang T, du J (2020) Energy- and environment-biased technological progress induced by different types of environmental regulations in China. Sustainability 12(18)

Zhou X, Wang L, Du J (2021) Institutional environment and green economic growth in China. Complexity 2021:6646255

Publisher's note Springer Nature remains neutral with regard to jurisdictional claims in published maps and institutional affiliations. 